\title{
Interkoneksi Sufi Klasik Dan Kontemporer (Mengenal Sufisme Islam)
}

\author{
Oleh: Fitriadi Hi.Yusub \\ Institut Agama Islam As-Sidik Kie Raha Ternate \\ (Fitriadi667@gmail.com)
}

\begin{abstract}
Abstrak
Tulisan ini akan membahas tentang, "sufisme"Mengenal sufi Islam Tanpa Batas". Sufisme merupakan salah satu bagian daripengkajian Tasauf,paham ini didasarkan pada asumsi bahwa praktik-praktik dijalankan para penganutnya yang telah "dirumuskan" oleh kaum muslim terdahulu, yaitu para sahabat nabi saw,serta para tabiin, sebagaimana halnya orang-orang yang hidup setelah itu, dikonsepkan sebagai jalan menuju titik kebenaran. Hasil pengkajian ini menunjukkan bahwa: Pertama, Sufisme merupakan salah satu warisan ilmu pengetahuan Islam yang penting untuk di pelihara, dijaga serta mampu diperhatikan oleh umat Islam.Kedua, Perkembangan tarekat sufisme mengalami kemajuan, seiring dengan perkembangan waktu dari satu masa ke suatu zaman berikutnya. Sehingga menepis anggapan yang menganggap bahwa para sufi dan tarekatnya tidak akan mengalami perkembangan seiring dengan terjadinya modernisasi dan industrilisasi.Ketiga, Pengikut sufi memiliki ajaran yang sangat penting bagi pencarian ketenangan hati, yang disebut dengan uzlah. Uzlah atau pengasingan diri dari pergaulan masyarakat untuk mendekatkan diri kepada Allah.

Kata kunci: Sufisme, Tasauf, Islam
\end{abstract}

\begin{abstract}
This paper will discuss about SUFISM, "know the Sufis of Islam without borders". Sufism is one part of the study of Tasauf, this doctrine is based on the assumption that the practices executed her followers that have been "reformulated" by Muslims earlier, that the companions of the Prophet, as well as the taabi'een, as well as those who live after that, conceptualised as the way to point out the truth. This study aims to discover: Recognize the concept of Sufism Get to know the characters of traditional Sufi Thought and His congregation. The results of this study indicate that: Sufism is one legacy of Islamic science that is important to observe, guarded as well as being able to be noticed by the Muslims. the development of Sufism progress, along with the development of one period of time to a time of following him. So shook off the assumption to assume that the Sufis and his congregation will not experience the development along with the modernization and industrilisasi. The Nietzsche have
\end{abstract}


teachings that the search is very important for peace of mind, which is called uzlah. Uzlah or exile from his people to closer to God.

Key words: Tasawuf, Sufism, Islam.

\section{Pendahuluan}

Sufisme $^{1}$, sebagai aliran kebangkitan dan mistik dalam tradisi Islam, saat ini telah menjadi sasaran ketegangan modernisasi yang dialami seluruh dunia muslim, dan lebih khusus lagi Indonesia. Jadi, jelaslah bahwa artikulasi khazanah Islam yang berupaya menyelaraskan dengan modernitas penuh semangat di dunia muslim. Hal tersebut merupakan fenomena menarik yang berkembang di masyarakat kontemporer, khususnya di kota-kota besar. Maraknya bentuk wacana spiritual belakangan ini, pada masyarakat modernitas semakin haus dengan spiritualitas. Banyak dari mereka mengikuti tarekat di komunitas sufi yang memang dapat dijadikan satu cara menjaga kesucian jiwa, di tengah masyarakat yang kian diserang oleh gejolak pelepasan hasrat tanpa batas. Semua itu merupakan fenomena yang selalu ada dalam masyarakat manapun sebagai wujud dari pencarian identitas diri dan jiwa.

Peningkatan penduduk perkotaan yang cepat, penyebaran pendidikan umum nonreligius dan ilmu alam, pengikisan hierarki keluarga dan sosial perkampungan, penggantian kerajaan dengan kekuasaan rakyat, peningkatan mobilitas dan akses informasi. Semuanya itu, mendatangkan tekanan bagi komunitas masyarakat Muslim perkotaan untuk lebih ekstra dalam menjalani kehidupan yang semakin hari silih berganti problematika social,dan menarik, jika di satu pihak, Islam diserang dengan isu terorisme, maka di pihak yang lain, sufisme justru semakin digandrungi dan menjadi ajang pencaharian ketenangan batin atau jiwa.

Sufisme yang pernah dituduh sebagai biang keladi (pokok masalah) kemunduran umat Islam, bertentangan dengan etos modernisme, dan dianggap termasuk oleh para sarjana Muslim sekaliber Fazlur Rahman, ${ }^{2}$ sebagai afiltrasi budaya luar yang menggerogoti Islam. Akan tetapi, berbeda dengan sekarang, tidak seperti yang selalu

\footnotetext{
${ }^{1}$ Ibnu Khaldun mengatakan, bahwa "Sufisme" adalah salah satu dari ilmu-ilmu tentang hukum agama yang berasal dari Islam. Paham ini didasarkan pada asumsi bahwa praktik-praktik yang dijalankan oleh para penganutnya telah "dirumuskan" oleh kaum muslim terdahulu, yaitu para sahabat nabi saw. Serta para tabiin, sebagaimana halnya orang-orang yang hidup setelah itu, sebagaii sebuah jalan menuju kepada kebenaran, lihat dalam, Carl.W.Erns, Ajaran dan Amaliah Tasawuf, terj. Arif Anwar dkk, (Jogjakarta: Pustaka Sufi), III.

${ }^{2}$ Lebih jelas Baca dalam karya Rahman tentang "Islam" penerjemah, Ahsin Mohamad (Bandung: Penerbit Pustaka), 183-217.
} 
dipikirkan oleh umat Muslim pada umumnya, karena kini para sufi menjadi semacam trend, bagi sebahagian kalangan orang-orang di perkotaan. Lahirnya berbagai komunitas di kota-kota besar dengan latar belakang berbeda dan memunculkan perilaku spiritualitas yang di sebahagian kelompok lain menganggap sebagai penyesatan dalam peribadatan agama.

Bagi sementara kalangan Muslim, sufisme atau tasawuf tidak relevan dengan kemodernan dan semua yang berkaitan dengan itu. Bahkan, sebaliknya, sufisme mereka pandang sebagai hambatan bagi kaum Muslimin dalam mencapai kemodernitas dan kemajuan dalam berbagai lapangan kehidupan. Karena itu, jika kaum Muslimin ingin mencapai kemajuan, maka sufisme dalam berbagai bentuknya haruslah ditinggalkan. Karena kemunduran dan keterbelakangan kaum Muslimin adalah terperangkap ke dalam berbagai praktik sufistik memabukkan, yang membuat mereka lupa akan kehidupan dunia. Pandangan ini menempatkan sufisme sebagai "tertuduh" dan bukanlah sesuatu yang baru.

Berlainan dengan konsepsi negatif diatas bahwa kebangkitan modernisme dan reformisme Islam sejak awal abad ke-20 menjadikan tasawuf sebagai salah satu sasaran pembaharuan dan pemurnian Islam. Bagi para pemikir dan aktivis modernis dan reformis Muslim, kaum Muslim bisa mencapai kemajuan hanya dengan meninggalkan kepercayaan dan praktik sufistik yang mereka pandang bercampur dengan bid'ah, khurafat, takhayul, dan taqlid buta kepada pimpinan tasawuf dan tarekat. Boleh jadi pemahaman semacam ini bisa benar, namun tidak menutup kemungkinan ucapan tersebut juga salah. Perlu dijeskan sekali lagi bahwa usaha dan pengkajian terhadap sufisme adalah khazanah keilmuan yang selalu di pelajari dalam berbagai perkembangan zaman.

Pandangan-pandangan seperti itu, (pandangan negatif terhadap sufisme) tampaknya perlu dikaji ulang, setelah lebih dari setengah abad Negara-negara dan masyarakat-masyarakat muslim mengalami proses modernisasi. Modernitas dan modernisasi tidak selalu berhasil memenuhi janji-janjinya bagi peningkatan kesejahteraan kaum muslimin, baik secara lahir maupun batin. Sebaliknya, modernisasi yang kemudian diikuti globalisasi yang tidak terbendung memunculkan kesulitankesulitan baru dalam kehidupan, mulai dari meningkatnya gaya hidup materialistik dan hedonistik, sampai kepada disorientasi dan dislokasi sosial, politik serta budaya. 
Sehingga tidak bisa dikatakan bahwa sufisme adalah akar masalah kemunduran umat Islam dewasa ini, realitas menunjukkan kalau sufisme telah mengalami perkembangan dan kebangkitan. Hal tersebut sudah lama terjadi, Semenjak pada masa pascamodernitas dan globalisasi ini, tidak hanya di dunia Indonesia, tetapi juga di hampir seluruh kawasan dunia muslim, bahkan sampai dunia muslim barat.

\section{Mengenal Sufisme dan Pemikirannya}

a. Pegertian dan Pandangan Tokoh Islam tentang Sufi

Kata sufisme berasal dari awalan kata Sufi, berasal dari bahasa Arab, ashshufiyyun, yang artinya sufi atau ahli. ${ }^{3}$ Ahli di sini memiliki makna seseorang yang mempunyai keilmuan dalam bidang tasawuf. Dalam khazanah keilmuan tasawuf, peran sesorang sufi sangat berarti bagi kelangsungan dan perkembangan keilmuan tersebut. Al-Hujwiri ${ }^{4}$ menyatakan bahwa sufi adalah sebuah nama yang diberikan kepada wali-wali dan ahli-ahli keruhanian yang murni. Ibnu Khaldun mengatakan:

"Sufisme adalah salah satu dari ilmu-ilmu tentang hukum agama yang berasal dari Islam. Paham ini didasarkan pada asumsi bahwa praktik-praktik yang dijalankan oleh para penganutnya telah “dirumuskan” oleh kaum muslim terdahulu, yaitu para sahabat nabi saw. Serta para tabiin, sebagaimana halnya orang-orang yang hidup setelah itu, sebagaii sebuah jalan menuju kepada kebenaran,"5.

Ibnu Khaldun menjelaskan dengan defenisinya sendiri, bahwa sufi merupakan hasil karya umat Islam yang telah ada pada masa nabi Muhammad, para sahabat dimasa awal lahir dan perkembangan Islam. Dengan melihat fakta sejarah yang ada, kebenaran sebuah pendapat tentunya sangat bervariatif, kita bisa saja membenarkan defenisi yang disampaikan oleh para tokoh-tokoh muslim, seperti

\footnotetext{
${ }^{3}$ A.W.munawwir dan Muhammad fairuz, Kamus Al-Munawwir Indonesi-Arab Terlengkap (Surabaya: Pustaka Progresif, 2007), 831.

${ }^{4}$ Menurutnya, pengikut sufi ada tiga derajat, yaitu al-Sufi, al-Mutasawwif, al-Mustaswif. al-Sufi adalah orang yang mati pada dirinya dan hidup oleh yang maha benar (al-haqq), Al-Mutasawwif adalah orang yang berusaha keras mencapai tingkatan ini (para sufi) dengan cara menundukkan hati dan hawa nafsu. Dalam pencariannya, ia meluruskan tingkahlakunya sesuai dengan teladan para sufi. Sedangkan al-Mustaswif adalah orang yang membuat dirinya secara lahiriah serupa dengan para sufi untuk sekedar cara uang, kekayaan, kekuasaan, serta keuntungan duniawi, dan sedikit sekali mempunyaipengetahuan serta tidak mengamalkan kesufian, lebih jelas baca dalam, Dahlan Tamrin, Tasawuf Irfani, Tutup Nasut Buka Lahut (Malang: UIN-Maliki Press, 2010),11.

${ }^{5}$ Ibid.
} 
Ibnu Khaldun tersebut. Walaupun demikian, semua itu bukan berarti menjadi tolak ukur untuk menerima segala interpretasi yang di paparkannya, karena obyektivitas maupun subjektivitas sebuah masalah pasti memiliki keganjilan jika tidak dilihat secara luas. ${ }^{6}$

Dalam perkembangan kehidupan Islam di Indonesia,nampak gejala semakin luasnya perhatian publik dan cendekiawan terhadap pemikiran dan praktik sufi. Namun demikian, beda praktik hidup berdasarkan cara sufi dan aturan syariah, hingga kini belum juga terjenihkan secara tuntas. Hal ini memerlukan penafsiran baru teks-teks suci Islam dan sejarah Islam itu sendiri. Untuk itu penting dikembangkan suatu pemahaman baru tentang relatifitas penafsiran Islam, dengan meletakkan kemutlakan kebenaran hanya pada Tuhan. ${ }^{7}$

b. Pandangan Umum tentang Sufi

Sufisme asal kata dari sufi, Noldeke berpendapat kata sufi berasal dari kata suf (bahasa arab) yang berarti bulu domba, seperti pertapa (asketis) yang meniru kehidupan biarawan Nasrani, menggunakan pakaian dari anyaman bulu domba yang kasar sebagai tanda tobat dan meninggalkan kehidupan duniawi. ${ }^{8}$ Sufisme adalah subyek yang tidak mudah didekati, seperti halnya fenomena religious non-Eropa lain yang sedemikian kompleks. Apa yang kini kita sebut sebagai sufisme bukanlah sebuah kajian yang primer bagi orang-orang Eropa sebelum zaman modern ini. ${ }^{9}$ Baru selama dua abad terakhir orang-orang Eropa (Amerika) mulainya memperhatikan dan tertarik secara serius agama-agama di dunia, sebagai subyek yang diteliti. Ketertarikan orang-orang Eropa kepada agama non-Kristen tumbuh berkat penaklukan-penaklukan serta kolonialisme yang merupakan tujuan utama kebijakan bangsa-bangsa Eropa ketika masa itu.

Jika melihat secara historis, orang-orang Eropa memiliki pandangan dan defenisii tersendiri berhubungan dengan sufisme, Dua istilah yang paling bisa mewakili sikap bangsa Eropa terhadap sufisme adalah fakir (dari bahasa Arab fakir)

\footnotetext{
${ }^{6}$ Sebagai bandingan dari pendapat Ibnu Khaldun, Sir William Jones, mengatakan "Bahwa teologi metafisik, yang sejak dahulu kala sudah dianut oleh banyak sekte Persia dan hindu-india, telah dimasukkan ke yunani, dan hingga sekarang masih berlaku, bahkan di kalangan muslim terpelajar, yang terkadang mengakuinya begitu saja tanpa sikap waspada, para filsuf modern yang menganut kepercayaan ini disebut sufi.

${ }^{7}$ Abdul Munir Mulkhan, Ajaran dan Jalan Kematian Syekh Siti Jenar (Yogyakarta: Kreasi Wacana, 2004), 1.

${ }^{8}$ Annemarie Schimmel, Dimensi Mistik dalam Islam, terj. Supardi Djoko Darmono dkk, (Jakarta: Pustaka Firdaus, 2000), 8 .

${ }^{9}$ Carl.W.Erns, Ajaran dan Amaliah Tasawuf, 1.
} 
dan darwis (dari bahasa Persia darvish). Kedua kata tersebut memiliki arti yang kurang lebih sama; fakir adalah glosarium Arab yang bermakna "orang fakir" sedangkan darvish adalah istilah Persia yang bermakna sama. Para pengembara Eropa sejak abad 16 telah mendeskripsikan para darwis sama maknanya dengan para rahib dan biarawan Katholik, karena gaya hidup mereka yang menyendiri.

Sementara bagi para penganut protestan, perbandingan ini sudah cukup untuk menuding darwis sebagai wujud penyimpangan yang menyolok dalam cara beragama. Dengan melihat berbagai pandangan yang didefenisikan oleh para kelompok-kelompok sektarian tersebut. Sesuai dengan pengertian yang disampaikan diatas, saya ingin kutipkan segelumit ungkapan Syekh Syihabud-Din “Ahmad Najib Burhani pada pendahuluan bukunya 'Sufisme Kota'

Seorang fakir atau sufi, mesti meninggalkan gagasan tentang kepemilikan duniawi, hidup dalam penuh keserasian dengan saudara-saudaranya, mencintai mereka, dermawan dan terus waspada mengenai ucapan nabi saw. Berilah siapa saja yang meminta, meski ia datang dengan mengendarai kuda, ramah dan santun, berwatak pertengahan, selalu menampilkan wajah yang penuh senyum, menerapkan keadilan yang setinggi-tingginya terhadap saudara, memelihara keseimbangan yang pas antara juhud (hidup sederhana) yang berlebihan dan hidup terlalu enak. ${ }^{10}$

Lain halnya dengan argument diatas, Istilah fakir memiliki sejarah yang lebih panjang dan rumit, karena para pejabat kerajaan Mughal di India, yang merupakan penulis berbahasa Persia,mereka menggunakan istilah tersebut untuk memberikan gambaran tentang para pertapa non-Muslim. Seperti yogis, juga para sufi pertapa dan pengembara. Sementara orang-orang Inggris mewarisi terminologi ini ketika mereka menguasai sebagian besar India, dalam bahasa Inggris abad 19, fakir atau faker dipakai hampir secara eksklusif untuk menyebut para pertapa Hindu. Baik berasal dari persekutuan monarki terorganisir maupun yang digambarkan oleh orang Ingris sebagai “bajingan-bajingan yang keluyuran di jalan-jalan.

Walaupun sebagian kalangan menginterpretasi istilah sufisme kepada arah makna yang terkesan kolot dan marjinal. Dalam konteks aslinya, darwis dan fakir adalah istilah-istilah yang mengacu pada kemisinan spiritual (spiritual poverty),

${ }^{10}$ Ahmad Najib Burhani, Sufisme Kota (Jakarta: Serambi Ilmu Semesta, 2001). 23 
tidak memiliki apa pun atau sangat lemah di hadapan Tuhan. Oleh karenanya, menjadi sangat tergantung kepada-Nya. Sebagaimana dalam tradisi religious lain, kemiskinan bagi para sufi adalah tanda ketidak peduliaan terhadap Dunia dan perhatian terhadap realitas ketuhanan. ${ }^{11}$ Untuk kalangan umat Islam, sebagian kelompok dengan tegas memberikan argumen secara tegas yang penuh kontra. Salah satu kelompok yang tidak sejalan dengan para sufisme adalah orang-orang yang berusaha untuk melaksanakan ajaran al-Quran sesuai dengan cara yang dilakukan oleh nabi Muhammad, mereka adalah kaum salaf. Sufisme dan salafisme umumnya telah di paparkan sebagai manifestasi Islam yang saling berlawanan dan karenanya kedua kelompok tersebut selalu memberikan pandangan saling bertentangan.

Pada kesempatan lain, kelompok salaf (wahabi) memandang para sufi sebagai kalangan penistaan agama, ritual sufisme adalah sesat. Namun, Pada kenyataannya, kaum sufi berusaha untuk menjawab semua tuduhan tersebut dengan melakukan berbagai kegiatan peribadatan yang dapat menarik simpatik masyarakat Islam, sehingga dalam kurung waktu pasca-modernitas mengalami perkembangan signifikan, utamanya di pusat perkotaan. Hal demikian, tentu kita teringat dengan anggapan sementara ahli yang pernah memprediksikan bahwa sufisme tidak dapat bertahan di tengah modernisasi dan kemudian globalisasi. Pada sisi lain, di ingatkan dengan penjelasan yang diutarakan oleh Van Bruinessen dan Howwel, beranggapan bahwa kebangkitan tidak bisa sepenuhnya dipahami hanya sebagai suatu bentuk respon kaum sufi terhadap modernitas dan globalisasi. ${ }^{12}$

\section{Mengenal Pemikiran Sufisme Tanpa Batas}

Dalam dunia sufisme, terdapat beragam tarekat yang dikenal, baik lingkup satu wilayah geografis maupun sebaliknya. Dengan demikian, penulis ingin menyajikan beberapa tarekat sebagai pembahasan kajian ini.

\footnotetext{
${ }^{11}$ Carl.W.Ernst, Ajaran dan Amaliah Tasawuf, 5.

${ }^{12}$ Mengingat jumlah studi empiris yang semakin meningkat menunjukkan bahwa klaim para pengkaji komunitas muslim yang mengalami modernisasi pada 1960-1970 mengenai kemunduran tarekat tidak tidak dapat lagi dipertahankan. Justru semakin terbukti bahwa tarekat tidak hanya sanggup bertahan, tetapi juga bisa berperan secara berarti dalam masyarakat modern. Dengan begitu menolak pandangan bahwa sufisme, kalau bukan agama secara umum bertentangan dengan modernitas. Namun, para penulis kajian empiric, kalangan ini dihadapkan pada kesulitan mengembangkan kerangka teoritis yang lebih tepat untuk menjelas inti hubungan antara sufisme dan modernitas. Lihat Sinopsis Buku Martin Van Bruinessen dan Julia Day Howel," Urban Sufism" 577 Halaman, Pengantar Oleh Azyumardi Azra, (Jakarta: Rajagrafindo Persada, 2008).
} 
Asal kata "tarekat" dalam bahasa Arab ialah "thariqah" yang berarti jalan, keadaan, aliran, atau garis pada sesuatu. ${ }^{13}$ Sementara menurut Harun Nasution, tarekat berasal dari kata Thariqah, jalan yang harus ditempuh oleh seorang calon sufi dalam tujuannya berada sedekat mungkin dengan Allah. Jhon O. Voll menambahkan, istilah tarekat digunakan untuk organisasi sosial maupun kewajiban-kewajiban yang ditujukan untuk maksud khusus menjadi basis ritual dan struktur kelompok. Dengan demikian kelompok sufi mencakup spektrum aktivitas yang luas dalam sejarah dan masyarakat muslim. ${ }^{14}$ Sejalan dengan ini, Martin Van Bruinessen menyatakan bahwa istilah tarekat paling tidak dipakai untuk dua hal, secara konseptual berbeda. Makna yang asli merupakan paduan yang khas dari doktrin, metode dan ritual. Akan tetapi, istilah ini pun sering dipakai untuk mengacu kepada oraganisasi yang menyatukan pengikut-pengikut, jalan tertentu. Di Timur Tengah, istilah Tha'ifah terkadang lebih disukai untuk organisasi, sehinggah lebih muda untuk membedakan antara satu dengan yang lain. akan tetapi di Indonesia kata tarekat mengacu kepada keduanya. ${ }^{15}$ Berdasarkan penjelasan diatas, maka selanjutnya kita akan membahas tentang tarekat, dibawah ini ada beberapa tarekat yang dimuat, diantaranya:

a. Tarekat Qadiriyah

Qadiriyah adalah nama tarekat yang diambil dari nama pendirinya, Abdul Qadir Jailani. Tarekat ini menempati posisi yang sangat penting dalam sejarah spiritualitas Islam karena tidak hanya sebagai pelopor lahirnya oranisasi tersebut. Tetapi juga menjadi cikal bakal lahirnya berbagai cabang tarekat di dunia Islam. ${ }^{16}$

\section{b. Tarekat Syadziliyah}

Pendiri Tarekat Syadziliyah adalah Abu Al-Hasan Asy-Syadzili tarekat ini banyak menyebar luas disebagian besar Dunia muslim. Terutama Afrika Utara dengan cabang-cabangnya seperti fasiyah dan darqawiyah serta perkebangannya di wilayah Mesir. $^{17}$

c. Tarbekat Naqsabandiyah

\footnotetext{
${ }^{13}$ M.Solihin dan Rosihon Anwar, Ilmu Tasawuf, (Bandung: Pustaka Setia, 2011), cet 2, 203.

${ }^{14}$ John 1. Esposito, Ensiklopedi: Dunia Islam Modern, Jilid 5, Cet 1, Terj, Eva Y.N dkk, (Bandung: Mizan, 2001),215.

${ }^{15}$ Martin Van Bruinessen, Tarekat Naqsabandiyah (Bandung: Mizan, 1994), 61.

${ }^{16}$ M.Solihin dan Rosihon Anwar, Ilmu Tasawuf, 211

${ }^{17}$ Dan untuk saat ini di Indonesiapun sudah mulai berkembang,untuk mengenal tarekat Syadziliyah, silahkan baca dalam bukunya, K.H.Mohammad Rifai, Tarekat Syadziliyah langkah-langkah dan Amaliyahnya (semarang: CV Wicaksana, 2005).
} 
Tokoh pendiri dari tarekat ini adalah Muhammad Bahauddin an-Naqsabandi alAwisi al-Bukhari di Turkistan. Ciri menonjol tarekat ini yaitu keseriusan dalam beribadah mengikuti syariat secara ketat, sehingga menyebabkan mereka kepada penolakan terhadap musik dan tarian. Keseriusan mendekati kehidupan dan peikiran golongan penguasa serta mendekati Negara pada agama, berusaha melancarkan konfrontasi dengan berbagai kekuatan poitik agar mengubah pandangan mereka.

d. Tarekat Yasifiyah

Tarekat ini didirikan oleh Ahmad Al-Yasafi, turki merupakan daerah perkembangan Tarekat Yasifiyah. Pada masa kejayaan turki usmani kelompok ini pernah memegang peranan penting yang pada saat itu dipelopori oleh murad $1 .^{18}$ Kenyataan tersebut sebagaimana di katakan bahwa pada masa kesultanan Usmani hingga 1923 dan sesaat pada masa Republik Turki, tarekat sufi memiliki arti sangat penting bagi kehidupan sosial, politik dan ekonomi. ${ }^{19}$

e. Tarekat Khalwatiyah

Pendiri tarekat lni adalah Umar Al-Khalwati, merupakan salah satu tarekat yang berkembang di berbagai wilayah. Sperti, Turki, Suria, Mesir, Hijaz, dan Yaman. Dari tarekat ini kemudian berkembang di daerah-daerah lain dengan masing-masing pendiri. Disamping itu, saya ingin memberikan sedikit penjelasan tentang tarekat Khalwatiyah dan perkembangannya di Mesir. Meskipun tarekat Khalwatiyah berasal dari TurkiPersia, namun pada kenyataannya Mesir merupakan pusat perkembangan terpenting oleh kelompok tarekat ini. Dalam pandangan mereke, seorang Syaikh dapat memiliki fungsi yang sama dengan khalifah, sebagai wakil Tuhan di muka Bumi. ${ }^{20}$

\section{Tarekat dan Pemikiran Sufi Tradisional}

Penulis ingin memaparkan secara lugas mengenai dengan makna sufi tradisional, Ahl al-shuffahyaitu kelompok sahabat yang mengikuti hijrah Nabi dari Makkah ke Madinah, dengan meninggalkan seluruh harta bendanya. Setelah di Madinah mereka

\footnotetext{
${ }^{18}$ M.Solihin dan Rosihon Anwar, Ilmu Tasawuf, 213

${ }^{19}$ Martin Van Bruinessen dan Julia Day Howel," Urban Sufism, 89.

${ }^{20}$ Ibid, 46.
} 
hidup dalam kondisi miskin. Tinggal di emperan Masjid Nabi dan tidur di atas bangku batu dengan memakai shuffah (pelana kuda) sebagai bantal. Pelana disebut suffah yang identik dalam bahasa Inggris saddle-cushion dan kata sofa-Kursi panjang yang bisa digunakan untuk tidur atau duduk bersantai. Secara umum para sahabat Nabi mereka berhati mulia serta baik, dan tidak mementingkan kehidupan keduniaan.

Sufi dari kata shafiy dan shafa, yaitu suci. Sehingga seorang sufi adalah orang yang disucikan sedangkan kaum sufi merupakan orang-orang yang telah mensucikan dirinya melalui latihan dalam ibadah, terutama shalat serta puasa, dimana tujuan hidup mereka adalah membersihkan lahir dan batin menuju magfirah dan ridah Allah. ${ }^{21}$ Sebagaimana Sahl Bin Abdullah At-Tustari memberi defenisi:

Seluruh kebaikan itu telah terkumpul dan terhimpun pada empat sifat utama yang harus ada pada diri seorang sufi sejati. Kebaikan para abdal (para pengganti) akan tetap selalu menjadi abdal selama mereka selalu berpegang teguh dengannya. Adapun keempat sifat sufi tersebut adalah mengosongkan perut, diam, menyepi (berkhalwat) dan melakukan begadang malam atau tidak tidur di malam hari. $^{22}$

Dalam dunia tasawuf, para sufistik memiliki ajaran yang sangat penting bagi pencarian ketenangan hati, yang dimaksud dari ajaran sufi tersebut adalah $u z l a h .{ }^{23}$ Uzlah atau pengasingan diri dari pergaulan masyarakat untuk mendekatkan diri kepada allah, tetapi perlu dikatahui bahwa hal ini bukan berarti seorang sufi secara terus-menerus menjauhkan dari tempat keramaian hingga meninggalkan seluruh kehidupan dunia, sebab uzlah tidak harus dilakukan selamanya dalam mengarungi kehidupan di dunia, melainkan pada saat seorang menginginkan agar kekacauan, kerisauan hati dan pikiran yang menyelimutinya semakin menyuguhkan, sehingga jalan terbaik adalah uzlah. Uzlah merupakan sarana untuk melakukan introspeksi diri, merenungkan kelemahan dan kelebihan, kegagalan dan keberhasilan, kemaksiatan dan ketaatan yang pernah dilakukan. dengan maksud supaya kelemahan, kegagalan diperbaiki, kemaksiatan ditinggalkan, sedangkan kelebihan, keberhasilan serta ketaatan kepada Allah harus

\footnotetext{
${ }^{21}$ Muhammad Sholikhin, Tradisi Sufi dari Nabi, Tasawuf Aplikatif Ajaran Nabi Muhammad saw. (Yogyakarta: Cakrawala, 2008), 19.

${ }^{22}$ Abdurrahman Abdul Khaliq dan Ihsan Ilahi Zhahir, Pemikiran Sufisme dibawah Bayang-Bayang Fatamorgana (Jakarta: Amzah, 2001), 44.

${ }^{23}$ Sudirman Teba, Tasawuf Positif (Jakarta: Prenada Media, 2003), 6.
} 
ditingkatkan. Seperti halnya para ahli ilmu kalam dan berbeda dengan filosof, kaum sufi memberikan tempat yang penting terhadap al-Quran dan Hadis Nabi. Hanya saja mereka berpandangan bahwa satu-satunya jalan untuk memahami pesan wahyu adalah mensucikan hati agar layak dan pantas diajari oleh Allah sendiri. ${ }^{24}$

Istilah sufi dan tasawuf berangsur-angsur baru dikenal setelah abad ke-2 $\mathrm{H}$. Namun, sebenarnya sejak zaman Nabi sudah dikenal sebutan-sebutan qari’, zahid, nasik, dan 'abid. Masing-masing mempunyai arti orang yang ahli membaca dan menjalankan isi al-Quran, orang yang teliti mengamalkan Ibadat, beramal Islami tidak terlepas dari amal syar'inya, baru kemudian disusul kata sufi sebagai nama mereka. Suhrawardi menceritakan bahwa sejak awal Islam sudah banyak manusia yang tinggal di pinggiran Kota dan di kaki Gunung, menjauhi perkotaan dan keramaiaan. Orang Persia menamainya sebagai Syaktafiyyah, dimana kata ini di khurasan berarti Gua. Sementara di Syam menamainya Ju'iyyah penderita lapar.

Pada pembahasan berikutnya, beberapa tokoh sufistik awal yang penulis kemukakan dalam penulisan ini. Para tokoh sufi tersebut bermula dari awal berkembangnya Islam hingga pada era modern, kiranya sangat banyak jika pembahasannya tidak di batasi, Tokoh-tokoh sufi tersebut, diantaranya sebagai berikut:

a. Sayyida Ali Bin Abi Thalib (35-40 H/ 656-661 M)

Ali dikenal sebagai seorang yang gagah berani serta memiliki kerohaniaan yang subur. Pekerjaan dan dedikasi serta cita-cita yang sangat besar sehingga menyebabkan begitu mendalam kecintaan terhadap kehidupan akhirat. Jiwa yang tidak terlalu mementingkan keuntungan duniawi, Sampai-sampai Dia tidak memperdulikan pakaian yang dipakainya telah robek karena mumuk. Sehingga, ada sebagian orang bertanya kepada Beliau, "mengapa sampai begini, ya amirul mukminin ?" maka dijawab, untuk mengkhusukkan hati dan menjadi teladan bagi orang yang beriman. Sifat yang begitu bersaja dan kezuhudannya yang begitu tinggi sehingga dalam berbagai tarekat sufi sangat mengidolakan beliau, bahkan nama Ali menjadi otoritas di bawah nabi Muhammad saw.

b. Abu Mansur Al-Hallaj

${ }^{24}$ William C.Cittick, Tasawuf di Mata Kaum Sufi (Bandung: Mizan, 2002), 71. 
Nama lengkap sufi legendaris ini adalah Abu al-Mughits al-Husain bin Mansur bin Muhammad Al-Baidhawi (244 H/858 M),Ia lebih dikenal dengan nama Al-Hallaj. Dalam kegiatan sufistiknya yang begitu mendalam dan kontraversi menurut para penguasa saat itu, sehingga akhir dari kehidupannya adalah menerima hukuman mati. ${ }^{25}$ Pandangan Al-Hallaj tentang al-Hulul dengan substansinya Mengenal Allah, berkaitan dengan akidah sufi, mengenal Allah di dalam dunia sufisme dikenal istilah al-Hulul, suatu paham akidah yang menyebutkan bahwa Allah memilih tubuh-tubuh manusia tertentu untuk mengambil tempat di dalamnya.

Bagi sufi, manusia adalah penampakan lahir dari cinta tuhan yang azali kepada zat dan esensi-Nya, yang mutlak dan tidak mungkin untuk disifatkan. Oleh Karen itu, manusia diciptakan tuhan dalam rupa-Nya, sehingga "ia adalah Dia" dengan kata lain di dalam tubuh manusia terdapat sifat-sifat kemanusiaan. Oleh kalangan sufi, biasa diistilahkan dengan kata an-Nasut dan terdapat pula sifat ketuhanan yang disebut al-Lahut. Tegasnya, apabila manusia telah dapat menghilangkan sifat-sifat kemanusiaan dari dalam dirinya dengan jalan fana, maka akan tinggallah di dalam dirinya sifat-sifat ketuhanan. Sehingga ketika itulah tuhan akan masuk ke dalam dirinya yang disebut al-Hulul. ${ }^{26}$

c. Rabiah Al-Adawiyyah

Wali wanita ternama dari basrah, dikenal kemasyhurannya sebagai orang yang membedakan pecinta tuhan egois untuk mencari surga dan pencinta sejati yang menganggap Tuhan semata sebagai kekasihnya. Bagi dia, cinta (hub atau mahabba) bermakana konsentrasi kepada tuhan untuk membuang segala yang lain. Ketika Sufyan As-Sawri bertanya kepada Rabi'ah “ apa sesungguhnya hakikat dari keimanannya" ia menjawab, aku tidak menyembah Dia karena takut kepada api neraka, atau karena menginginkan surga-Nya sehingga aku menjadi budak rendahan. Namun, aku menyembah Dia karena cintaku dan kerinduanku kepada-Nya. ${ }^{27}$ Rabi'ah dikenal dengan instingsinya yang kerapkali disebut antara

\footnotetext{
${ }^{25} \mathrm{Hal}$ yang membuat al-hallaj di hukum mati adalah pendapatnya yang mengatakan bahwa "Ana al-Haqq" dan juga memiliki sifat ketuhanan, lebih jelas baca dalam, Muhammad Sholikhin, Tradisi Sufi Dari Nabi, .180-181.

${ }^{26}$ Abdurrahman Abdul Khaliq dan Ihsan Ilahi Zhahir, Pemikiran Sufisme, 23.

${ }^{27}$ Seyyed Hossein Nasr dkk, Warisan Sufi Sufisme Persia Klasik dari Permulaan Hingga Rumi (Yogyakarta:

Pustaka Sufi, 2002), . 511.
} 
'dua cinta' cinta egois, yang mencari surga dan cinta sejati, mencari kenikmatan tuhan. Hal demikian merupakan tingkatan-tingkatan cinta dalam pandangan Rabi'ah, Ia melanjutkan untaian kata-kata cintanya:

Aku mencintai-Mu dengan dua cinta, cinta egois dan cinta yang layak Engkau terima. Cinta egois adalah cintaku, dalam mengingat-Mu dan tiada lagi yang lain, tetapi demi cinta yang layak engkau terima. Ah, lalu engkau sibakkan selubung itu agar aku melihat-Mu. Tiada pujian untukku dalam cinta manapun, segala puji milik-Mu dalam cinta yang ini dan cinta yang itu. ${ }^{28}$

Meskipun dia tidak masuk ke dalam secara detail mengenai analisis cinta di luar distingsi dasar ini, Sufi Andalusia yang terkenal dan memiliki pengaruh besar pula Ibn Arabi berkata tentang Rabi'ah, dengan ungkapan bahwa dia adalah orang yang mengamati dan menggolongkan kategori cinta pada tingkatan dimana dia menjadi penafsir cinta yang paling masyhur. Puisi dan anekdot yang telah turun temurun kepada kita berkaitan dengan rabi'ah, diriwayatkan oleh para penulis dalam periode belakangan, namun demikian sungguh mengejutkan karena tradisi sufi dengan suara bulat memuji Rabi'ah disebabkan memiliki cirri has tersendiri dalam cinta dan menganggap dia sebagai contoh pecinta Tuhan yang sejati. bagi manusia yang mempunyai cinta kepada Allah dan tidak tulus ikhlas, maka Rabi'ah melukiskan lewat syai'rnya:

Dalam batin kepad-Nya engkau durhaka tetapi dalam lahir engkau nyatakan cinta. Sungguh aneh gejala ini, andaikan cinta-Mu memang tulus dan sejati tentu yang ia perintahkan kau taati, sebab pecinta selalu patuh dan bakti kepada yang dicintai. $^{29}$

Cinta atau Mahabba merupakan pijakan sebagai kemuliaan hal, seperti halnya tobat yng merupakan dasar bagi kemuliaan maqam. Karena mahabba pada dasarnya adalah anugerah sebagai pijakan segala segala macam persoalan, kaum sufi menyebutnya anugerah-anugerah mawahib. Suhrawardi menyatakan, sesungguhnya mahabbah adalah suatu mata rantai keselarasan yang mengikat sang Pecinta kepada kekasihnya, suatu ketertarikan kepada kekasih, menarik sang

\footnotetext{
${ }^{28}$ Ibid, .512.

${ }^{29}$ Abu Al-Wafa' Al-Ghanimi At-Taftazani, Sufi Dari Zaman Ke Zaman, terj, Ahmad Rofi' Utsmani, (Bandung: Pustaka, 1985), 86.
} 
pecinta kepadanya, dan melenyapkan suatu dari wujudnya. Sehingga pertamatama ia menguasai seluruh sifat dalam dirinya, kemudian menangkap zatnya dalam genggaman qudrah (Allah). ${ }^{30}$

d. Hasan al-Bashri

Nama lengkapnya Al-Hasan Bin Abi Al-Hasan Abu Sa'id (21 H/642 M), Putra dari Zaid Bin Tsabit. Disebutkan bahwa pada masanya, Ia selalu menentang para sahabat dari kalangan pejabat yang kehidupannya selalu berkelimpangan harta benda. ${ }^{31}$ Kemasyhurannya banyak disebutkan dalam literatur utama tokoh-tokoh sufi, dasar hidup yang diambil zuhud, wira'I, tawakal, khauf dan raja. ${ }^{32}$ Ia memandang bahwa seorang faqih haruslah seorang zahid, selalu beribadah kepada Allah, dunia seharusnya seseorang menjadikan tempat kerja. Namun, dengan perasaan tidak senang dan tidak membutuhkannya, sehingga terhindar dari penderitaan serta selalu bersikap sabar. an selalu berpesan kepada orang-orang agar tidak terkecoh oleh dunia sehingga akan mendatangkan kebijakan dan harus selalu yakin akan nasib akhir yang lebih baik. Sementara Abu Bakar Al-Wariq menerangkan istilah zuhud yaitu:

Zuhud adalah kata yang telah terdiri dari tiga huruf hijaiyah yaitu, zai yang mengandung pengertian meninggalkan segala perhiasan dunia. Huruf ha mengandung pengertian meninggalkan hawa nafsu. Huruf dal mengandung pengertian meninggalkan kehidupan dunia. ${ }^{33}$

Dalam khazanah sufi, sikap zuhud menjadi salah satu maqam terpenting, Apa yang dinamakan zuhud itu adalah kemauan membenci segala benda yang disenangi oeh nafsuh, Justru menghadapkan dirinya pada sesuatu tidak disenanggi oleh nafsu dan yang disenaggi oleh ruh, maksudnya adalah membenci dunia dan cinta kepada Allah semata atau senang akan akhirat. Namanya zuhud berarti orang yang membenci dirham, dinar serta harta benda yang lain. Bukan dinamakan zuhud, seorang yang memang tidak memiliki dirham, dinar, tidak punya harta benda, kemudian menyatakan dirinya zuhud maka hal itu adalah suatu

\footnotetext{
${ }^{30}$ Saikh Syihabuddin Umar Suhrawardi, 'Awarif Al-Ma'arif, terj. Lima Nugrahani Isma'il (Bandung: Pustaka Hidayah, 1988), 186.

${ }^{31}$ Muhammad Sholikhin, Tradisi Sufi dari Nabi, 170-171.

${ }^{32}$ Lihat Juga Dalam M. Solihin, .128.

${ }^{33}$ Abdurrahman Abdul Khaliq dan Ihsan Ilahi Zhahir, Pemikiran Sufisme, .45.
} 
kebohongan. Berharap dan takut (raja' dan khauf) bagi kalangan kaum sufi kedua komponen ini, berjalan seimbang dan saling memengaruhi raja' berarti berharap atau optimism, yaitu perasaan hati yang senang karena menanti sesuatu diinginkan dan disenangi.

e. Ibn 'Arabi

Nama lengkap Ibn Arabi adalah Muhyi Al-Din Abu 'Abd Allah Muhammad Ibn Ali Ibn Muhammad Ibn Ahmad Al-'Arabi Ali Al-Khatimi AthTha'I Al- Andalusia Ibn Al-'Arabi. ${ }^{34}$ Dalam sejarah pemikiran Islam ibn 'arabi dikenal sebagai tokoh penulis yang produktif, Ia dikenal dengan istilah ashshaykh al-akhbar. Salah satu teori dan pendapat yang terkenal adalah wahdatul wujud, dan salah satu teorinya menyebutkan bahwa Allah pada setiap sesuatu dan sebenarnya dialah setiap sesuatu itu. Karenanya, tidaklah ada sesuatu di alam dunia ini kecuali yang berhak untuk disucikan dan diagungkan. ${ }^{35}$

Ibn 'Arabi mengatakan bahwa hanya ada satu realitas ultima dalam seluruh penciptaan, dimana al-Haqq memanifestasikan dirinya dalam makhluk. Al-Haqq sebagai wajib al-wujud merupakan sumber segala realitas, yang tidak bisa dibagi-bagi, kekal, dan tidak berubah-ubah. Ia membedakan aspek tersembunyi tuhan yang tidak dapat diketahuii dan diperikan, merupakan aspek kesatuan (ahadiyah) dengan aspek ketuhanan (rububiyah), lewat mana Tuhan menjalin hubungan dengan dunia dan menjadi sebuah objek pemujaan sebagai yang dipertuan dan pencipta.

Dengan menambahkan bahwa yang maha benar adalah makhluk dan sekaligus bukan makhluk, ketika membantu Tuhan untuk memanifestasikan diri dan mengenal-Nya sang mistikus sebenarnya "menciptakan" Dia. Sementara Yang Maha Esa, muncul dalam bentuk bayangan di cermin, sebagaimana warna muncul dalam substansi. Ibn 'Arabi menambahkan, wajah sebenarnya satu tetapi jika engkau perbanyak cermin, ia menjadi banyak. ${ }^{36}$ Di dalam tiap cermin, Ia melihat dirinya dan dalam cermin tersebut dirinya kelihatan banyak.

\footnotetext{
${ }^{34}$ Muhammad Sholikhin Tradisi Sufi dari Nabi, .192.

${ }^{35}$ Abdurrahman Abdul Khalik dan Ihsan Ilahi Zhahir, .18-19.

${ }^{36}$ Muhammad Sholikhin, Tradisi Sufi dari Nabi, .199.
} 
Tetapi yang benar adalah dirinya hanya sendiri atau satu. Maka, berbagai objek di alam semesta ini adalah Tuhan namun dia tidaklah identik dengan objekobjek itu. Tuhan menjadi beraneka ragam hanya melalui sifat-sifat atau modifikasinya. Realitas ultima dan tertinggi dalam Ibn 'Arabi adalah hakikat ilahi, yang termanifestasikan melalui sejumlah nama Tuhan. Seorang mistikus tidak bisa mencapai tingkatan puncak ke-esaan (ahadiyah), yang menjadi milik hakikat. Dia hanya bisa mencapai tingkat ketauhidan (wahidiyyah), merupakan milik nama-nama Tuhan, Tuhan mengungkapkan diri-Nya kepada mistikus dengan menampilkan diri melalui satu nama dalam bentuknya yang absolute, sebagaimana dibedakan dengan manifestasi duniawi. ${ }^{37}$ selanjutnya kutipan pendapatnya Ibn 'Arabi.

Sudah menjadi kenyataan bahwa makhluk adalah dijadikan dan ia berhajat kepada Khaliq yang menjadikannya, karena ia hanya mempunyai sifat mungkin (mungkin ada mungkin tidak) dan dengan demikianwujudnya bergantung pada sesuatu yang lain; dan sesuatu yang lain tempat ia bersandar ini haruslah sesuatu yang ada pada esensinya mempunyai wujud yang bersifat wajib, berdiri sendiri dan tidak berhajat kepada yang lain dalam wujudnya; bahkan yang dalam esensinya memberikan wujud bagi yang dijadikan. Dengan demikian yang dijadikan mempunyai sifat wajib, tetapi sifat wajib ini bergantung pada sesuatu lain dan tidak pada dirinya sendiri. ${ }^{38}$

\section{Kesimpulan}

Sesuai dengan pemaparan materi di atas, maka sebagai simpulan: Dalam konteks masa kini, secara khusus,sufisme merupakan salah satu warisan ilmu pengetahuan Islamyang penting untuk di pelihara, perhatikan, oleh umat Islam dan menganggapnya sebagai bagian dari nilai histori untuk di ketahui. Perkembangan dalam tarekat sufisme mengalami kemajuan seiring dengan pergantian waktu. Untuk itu, berbeda dengan pandangan sebagian orang yang menganggap bahwa para sufi dan tarekatnya tidak akan mengalami perkembangan seiring dengan terjadinya modernisasi dan industrilisasi.Ironisnya, dalam dunia Islam, ada sebagian golongan yang

\footnotetext{
${ }^{37}$ Ibid, .199-200.

${ }^{38}$ Ibid,h. 200.
} 
mengklaim bahwa sufi adalah kelompok Islam yang merupakan faktor utama penyebab kemunduran umat Islam, Sufisme yang pernah dituduh sebagai biang keladi (pokok masalah) kemunduran umat Islam, bertentangan dengan etos modernism, oleh para sarjana muslim seperti Fazlur Rahman menganggapnya sebagai afiltrasi budaya luar yang menggerogoti Islam. Akan tetapi, berbeda dengan sekarang, tidak seperti yang selalu dipikirkan oleh umat muslim pada umumnya, karena kini para sufi menjadi semacam trend, bagi sebahagian kalangan orang-orang Islam di perkotaan. Mereka anggap sebagai suatu wadah untuk bermanifestasi ke jalan menuju Ilahi, karena dianggap sebagai sumber ketenangan batin yang ideal. 


\section{Daftar Pustaka}

Al-Ghanimi At-Taftazani, Abu Al-Wafa', 1985, Sufi Dari Zaman Ke Zaman. Terj. Ahmad Rofi' Utsmani, Bandung: Pustaka.

Bruinessen, van Martin, 1994, Tarekat Naqsabandiyah . Bandung: Mizan.

C.Cittick, William, 2002. Tasawuf di Mata Kaum Sufi. Bandung: Mizan.

Erns, Carl.W, 2003, Ajaran dan Amaliah Tasawuf, terj. Arif Anwar dkk, Jogjakarta: Pustaka Sufi.

Julia Day Howel, Martin Van Bruinessen, 2008, Urban Sufism. Jakarta: Jaragrafindo Persada.

Fairuz, Muhammad dan Munawwir.A.W, 2007, Kamus Al-Munawwir IndonesiArab Terlengkap. Surabaya: Pustaka Progresif,

Khaliq, Abdul Abdurrahman dan Zhahir Ilahi Ihsan, 2001. Pemikiran Sufisme dibawah Bayang-Bayang Fatamorgana. Jakarta: Amzah.

Hossein Nasr, Seyyed dkk, 2002. Warisan Sufi Sufisme Persia Klasik dari Permulaan Hingga Rumi. Yogyakarta: Pustaka Sufi.

Munir, Mulkhan Abdul. Ajaran dan Jalan Kematian Syekh Siti Jenar. Yogyakarta: Kreasi Wacana, 2004.

Najib, Burhani Ahmad. 2001. Sufisme Kota. Jakarta: Serambi Ilmu Semesta.

Tamrin, Dahlan. 2010. Tasawuf Irfani. Tutup Nasut Buka Lahut Malang: UinMaliki Press,

Rahman, Fazlur, . 2015. Islam, Bandung: Penerbit Pustaka.

Rosihon Anwar, M.Solihin, 2011. Ilmu Tasawuf. Bandung: Pustaka Setia.

Syihabuddin Saikh, Umar Suhrawardi, 1988. 'Awarif Al-Ma'arif. terj. Lima Nugrahani Isma'il . Bandung: Pustaka Hidayah,

Schimmel, Annemarie. , 2000. Dimensi Mistik dalam Islam. terj. Supardi Djoko Darmono dkk, Jakarta: Pustaka Firdaus.

Sholikhin, Muhammad, 2008. Tradisi Sufi Dari Nabi. Tasawuf Aplikatif Ajaran Nabi Muhammad Saw.Yogyakarta: Cakrawala. 